\title{
Study on Properties of Mortar and Concrete Using Belite-Gehlenite Clinker as Fine Aggregate
}

\author{
Hiromi Fujiwara ${ }^{1}$, Takaya Kawato ${ }^{1}$, Masanori Maruoka ${ }^{1}$, Masatoshi Nemoto ${ }^{1}$ and Kensuke Hayashi ${ }^{2}$ \\ 1. Design and Engineering for the Global Environment, Graduate School of Utsunomiya University, Tochigi 321-0904, Japan \\ 2. Taiheiyo Cement Corporation Central Research Laboratory 2-4-2, Osaku, Sakura City, Chiba Prefecture 285-8655, Japan
}

\begin{abstract}
In recent years, there has been a strong demand for sustainable concrete structures. In addition, the cement production has been a downward trend in Japan. However, the amount of wastes and by-products used for cement production has been increased. Therefore, it's necessary to explore new utilization of a cement clinker besides the cement. The Gehlenite clinker is produced from large amounts of recycled industrial waste, such as construction waste soil, sewage sludge, waste clay and coal ash. This study investigated the effect of using Gehlenite clinker as fine aggregate on various properties of mortar and concrete. The results show that, compared to mortar containing a conventional fine aggregate, mortar containing clinker aggregate has higher compressive strength, less drying shrinkage, and lower carbonation rate. In addition, mortar was evaluated by self-healing performance. Moreover, the properties of concrete are almost the same as mortar in compressive strength and drying shrinkage. In this paper, in order to investigate the mechanism of carbonation of mortar Gehlenite clinker was used as fine aggregate. The results show that, when the fine aggregate is replaced with Gehlenite clinker, the representative porosity in the transition zone is reduced by approximately half and this improves resistance to carbonation.
\end{abstract}

Key words: Gehlenite, clinker, drying shrinkage, self-healing, carbonation.

\section{Introduction}

In recent years, the population of Japan has declined, and there is a growing demand to create a sustainable society. Since early deterioration of concrete structures has become a social problem, there has been a strong demand for sustainable concrete structures, which does not rely on the traditional scrap-and-build.

In addition, the cement production in Japan has been a downward trend from a peak of 99,267 thousand tons in 1996. Due to the effort of cement companies in Japan, the amount of wastes and by-products used for cement production has been increased (Fig. 1). If the cement industry does not accept the wastes and by-products, which is an effective use in order to concentrate the final disposal site, the residual capacities of final disposal site is expected to be approximately 5 and a half years

Corresponding author: Hiromi Fujiwara, Ph.D., professor, research field: civil engineering. shorter than the estimate.

In Japan, there is a need to promote a recycling-oriented society. The cement industry providing basic industrial materials for a recycling-oriented society, as well as recycling the waste and by-products discharged from sectors of the economy.

Therefore, in order to use wastes effectively, it's necessary to explore new utilization of a cement clinker besides the cement.

Clinker is harder than general fine aggregate because clinker had burned granularly during manufacturing process. It is possible that clinker shows hydration reaction when it is mixed with water.

The Gehlenite clinker is produced from large amounts of recycled industrial waste, such as construction waste soil, sewage sludge, waste clay and coal ash. The chemical and mineral compositions of Gehlenite clinker are shown in Tables 1 and 2, respectively. Raw material used for sintering Gehlenite 


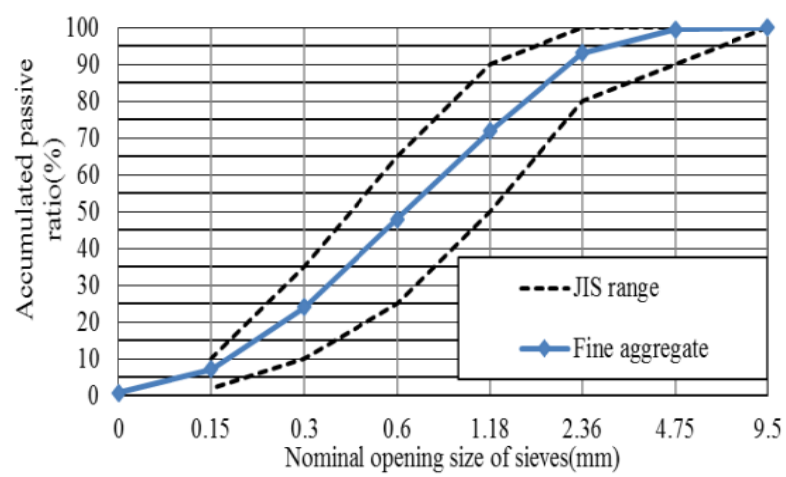

Fig. 1 Trends of cement production and in waste and by-products usage of cement industry.

clinker is produced by blending and pulverizing a virgin material (limestone, quartzite, etc.) with the industrial waste to obtain a mineral composition as shown in Table 2. Then the raw material was fed into the actual rotary kiln with a production rate at 2,000 tons as clinker per day. The burning temperature is around $1,200{ }^{\circ} \mathrm{C}$.

0.6 ton of waste is used to produce 1 ton of Gehlenite clinker. This means that the amount of waste of Gehlenite clinker is roughly twice as much as the one of ordinary Portland cement clinker commercially produced by Japanese cement plants. The main mineral of Gehlenite clinker is Belite as shown in Table 2.

Accordingly, this study used Gehlenite clinker as fine aggregate, and compared the basic properties and durability of mortar and concrete, and examined the possibility of concrete aggregate on self-healing for durability.

\section{Materials}

Ordinary Portland cement was used as a binder (symbol: C, density: $3.15 \mathrm{~g} / \mathrm{cm}^{3}$ ). Natural river sand was used for mortar ( $\mathrm{Sn}$, density in saturated surface-dry condition: $2.62 \mathrm{~g} / \mathrm{cm}^{3)}$, crushed sand was used for concrete ( $\mathrm{Sc}$, density in saturated surface-dry condition: $2.63 \mathrm{~g} / \mathrm{cm}^{3}$ ) and Belite-Gehlenite clinker (GCL, absolute dry density: $3.16 \mathrm{~g} / \mathrm{cm}^{3}$ ) was used as fine aggregate. Crushed stones ( $\mathrm{G}$, density: $2.64 \mathrm{~g} / \mathrm{cm}^{3}$ ) were used as coarse aggregate.

The particle size distribution of this fine aggregate was within the range defined in JIS A 5005 (Fig. 2) (equivalent to ASTM C33) [1]. Tap water (W) was used for mixing mortar and concrete. Poly-carboxylic acid-based high-performance air entraining and water reducing admixture (SP), air entraining admixture (AE) and an anti-foaming agent (DF) were also used.

\section{The Properties of Mortar Using Gehlenite Clinker as Fine Aggregate}

\subsection{Mix Proportions}

Table 3 shows the mix proportion of mortar. The volume ratios of GCL to total fine aggregate were $0 \%$, $25 \%, 50 \%, 75 \%$ and $100 \%$. The mortar flow value of 15 times tapping was adjusted within $150 \pm 30 \mathrm{~mm}$ by controlling the amount of SP.

\subsection{Testing Method}

\subsubsection{Fresh Property Test}

A mortar flow test was carried out in accordance with JIS R 5201 or ISO 679:2009 (equivalent to ISO 9597:2008) [2] and air volume measurement was carried out in accordance with JIS A 1116 (equivalent to ISO 6276:1982) [3].

\subsubsection{Compressive Strength Test}

Compressive strength tests were carried out in accordance with JIS A 1108 (equivalent to ISO 1920-4:2005) [4]. The compressive strength was measured at 7 th and 28th days after curing in water at $20{ }^{\circ} \mathrm{C}$. The test specimens were $\varphi 50 \mathrm{~mm} \times \mathrm{h} 100 \mathrm{~mm}$ in

Table 1 Chemical compositions of GCL.

\begin{tabular}{|c|c|c|c|c|c|c|c|c|}
\hline \multirow{2}{*}{ Symbol } & \multirow{2}{*}{ Ig.loss $(\%)$} & \multicolumn{7}{|c|}{ Chemical compositions $(\%)$} \\
\hline & & $\mathrm{SiO}_{2}$ & $\mathrm{Al}_{2} \mathrm{O}_{3}$ & $\mathrm{Fe}_{2} \mathrm{O}_{3}$ & $\mathrm{CaO}$ & $\mathrm{MgO}$ & $\mathrm{SO}_{3}$ & $\mathrm{Na}_{2} \mathrm{O}$ \\
\hline \multirow{3}{*}{ GCL } & \multirow{3}{*}{1.06} & 28.18 & 7.51 & 3.42 & 55.98 & 1.34 & 0.93 & 0.45 \\
\hline & & $\mathrm{K}_{2} \mathrm{O}$ & $\mathrm{Na}_{2} \mathrm{Oeq}$ & $\mathrm{TiO}_{2}$ & $\mathrm{P}_{2} \mathrm{O}_{5}$ & $\mathrm{MnO}$ & $\mathrm{Cl}$ & \\
\hline & & 0.58 & 0.83 & 0.41 & 0.89 & 0.11 & 0.047 & \\
\hline
\end{tabular}


Table 2 Mineral compositions of GCL.

\begin{tabular}{llll}
\hline Symbol & \multicolumn{3}{c}{ Mineral compositions (\%) } \\
\hline \multirow{2}{*}{ GCL } & $\mathrm{C}_{2} \mathrm{~S}$ & $\mathrm{C}_{2} \mathrm{AS}$ & $\mathrm{C}_{12} \mathrm{~A}_{7}$ \\
& 70 & 21 & 5 \\
\hline
\end{tabular}

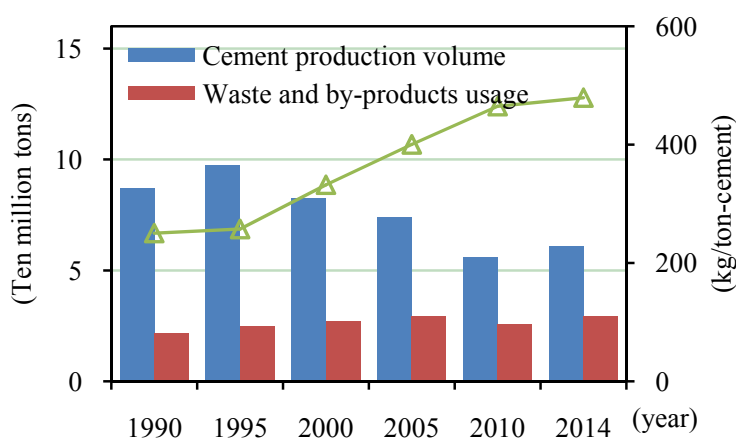

Fig. 2 Particle size distribution of fine aggregate (Natural river sand, crushed sand, GCL).

size and the number of specimens was three for each condition.

\subsubsection{Drying Shrinkage Test}

Drying shrinkage tests were carried out in accordance with JIS A 1129 (equivalent to ASTM C157) [5]. The test specimens were prismatic test specimens with $40 \mathrm{~mm} \times 40 \mathrm{~mm} \times 160 \mathrm{~mm}$ and the number of specimens was three for each condition. The tests were carried out after curing for 7 days in water at $20{ }^{\circ} \mathrm{C}$. The drying conditions were at temperature: $20{ }^{\circ} \mathrm{C}$ and relative humidity: $60 \%$.

\subsubsection{Accelerated Carbonation Test}

Accelerated carbonation test was carried out in accordance with JIS A 1153 (equivalent to ISO 1920-12:2015) [6]. The test specimens were prismatic test specimens with $40 \mathrm{~mm} \times 40 \mathrm{~mm} \times 160 \mathrm{~mm}$ and the number of specimens was three for each condition. The tests were conducted after curing for 28 days in water at $20{ }^{\circ} \mathrm{C}$, curing for 28 days in air at $20{ }^{\circ} \mathrm{C}$ and $60 \%$ relative humidity. The accelerated carbonation conditions were temperature: $20{ }^{\circ} \mathrm{C}$, relative humidity: $60 \%$ and carbon dioxide concentration: $5 \%$.

\subsubsection{Self-healing Ability Test}

The testing equipment is shown in Fig. 3. The test specimens were $\varphi 100 \mathrm{~mm} \times \mathrm{h} 200 \mathrm{~mm}$ in size and the number of specimens was three for each condition. The specimens were cured in water at $20{ }^{\circ} \mathrm{C}$ for 28 days. The specimens were then split into 2 pieces. To simulate cracks, Teflon sheets with $5 \mathrm{~mm} \times 5 \mathrm{~mm}$ and $0.3 \mathrm{~mm}$ in thickness were used as spacers to create gaps of $0.3 \mathrm{~mm}$. The spacers were inserted at the upper and lower ends of the cross-section and sandwiched tightly by stainless steel belts as shown in Fig. 3.

A synthetic resin adhesive was used to prevent water from leaking down from the sides of the specimens. A PVC (poly vinyl chloride) tube with an inner diameter of $100 \mathrm{~mm}$ was placed on top of the specimen as shown in Fig. 3. A drainage pipe was connected to maintain a water head height of $80 \mathrm{~mm}$ (the water pressure is about $0.8 \mathrm{kPa}$ ).

The water used in this test was a calcium hydroxide saturated solution with $\mathrm{pH}$ of 12.4 to prevent the elution of $\mathrm{Ca}^{2+}$ on the fracture surface of the mortar [7].

After pouring the water into the PVC tube, the amount of water leakage from cracks in the specimen was measured for 3 minutes. The measurement was carried out on setting days: $0,1,3,7,14,21$ and 28 days.

Table 3 Mix proportion of mortar.

\begin{tabular}{|c|c|c|c|c|c|c|c|}
\hline \multirow{2}{*}{ Mix name } & \multirow{2}{*}{$\begin{array}{l}\text { GCL/S }{ }_{n}^{*} \\
\text { vol. }(\%)\end{array}$} & \multirow{2}{*}{$\mathrm{W} / \mathrm{C}(\%)$} & \multirow{2}{*}{ Air (\%) } & \multicolumn{4}{|c|}{ Unit content $\left(\mathrm{kg} / \mathrm{m}^{3}\right)$} \\
\hline & & & & $\mathrm{W}$ & $\mathrm{C}$ & $\mathrm{S}_{\mathrm{n}}$ & GCL \\
\hline GCL0\% & 0 & & & & & 1,464 & 0 \\
\hline GCL25\% & 25 & & & & & 1,098 & 442 \\
\hline GCL50\% & 50 & 55 & $2 \pm 1.5$ & 267 & 485 & 732 & 883 \\
\hline GCL75\% & 75 & & & & & 366 & 1,325 \\
\hline GCL100\% & 100 & & & & & 0 & 1,766 \\
\hline
\end{tabular}

${ }^{*} \mathrm{GCL} / \mathrm{S}_{\mathrm{n}}$ : Volume ratio of Gehlenite clinker fine aggregate to total fine aggregate. 

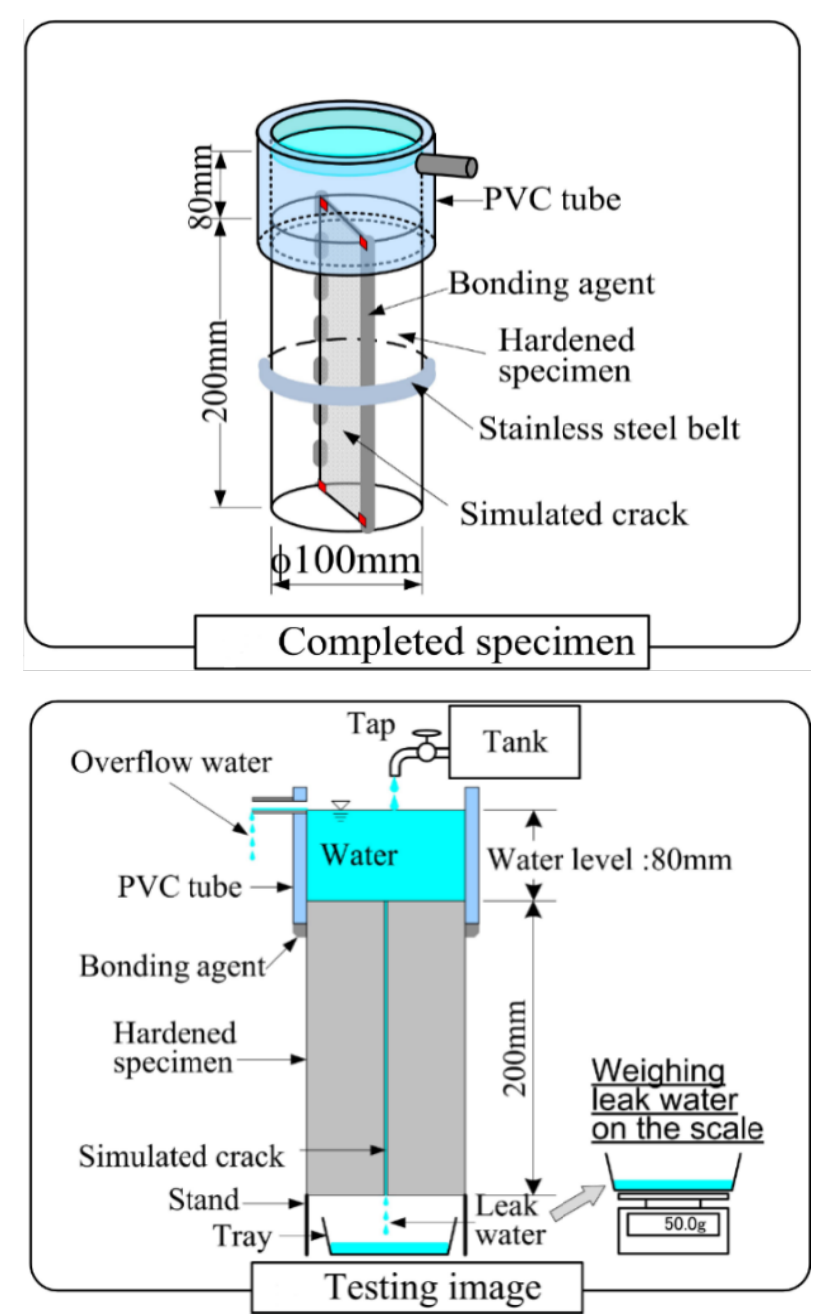

Fig. 3 Equipment for water leakage test.

Until testing, the specimens were stored in a calcium hydroxide saturated aqueous solution at 20 ${ }^{\circ} \mathrm{C}$. The rate of decrease in the amount of water leakage was calculated using Eq. (1).

Water leakage reduction rate $(\%)=\left(1-\frac{\alpha}{\beta}\right) \times$ 100

where, $\alpha$ is the measured amount of water leakage (g); $\beta$ is initial amount of water leakage $(\mathrm{g})$.

\subsection{Test Result and Discussion of Mortar Properties}

\subsubsection{Fresh Properties}

Fig. 4 shows the results of mortar flow test. Fig. 5 shows the air content of the mortar and Fig. 6 shows the additional rate for SP. As the GCL replacement ratio increases, in order to obtain a mortar flow value within the target range, it is necessary to increase the dosage of SP. When the GCL $/ \mathrm{S}_{\mathrm{n}}$ was $100 \%$, it was impossible to obtain a value within the target range. This is due to the shape of the GCL. The fine aggregate GCL is manufactured by pulverizing the original clinker so that each piece has an angular shape that negatively affects the fresh properties.

\subsubsection{Compressive Strength}

Fig. 7 shows results of the compressive strength test of mortar. As the replacement ratio of GCL increased, the compressive strength increased. This is due to the densification in transition zone, the interface between

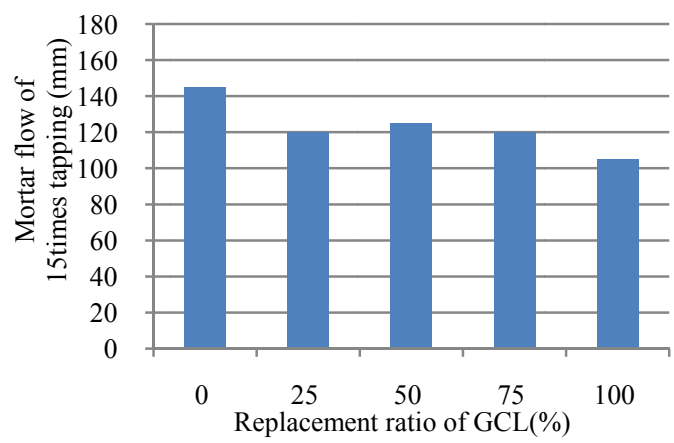

Fig. 4 Test results of mortar flow (15 times tapping).

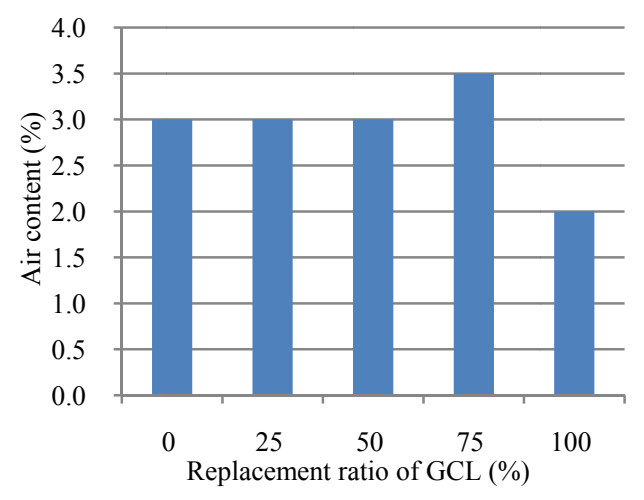

Fig. 5 Air content ratio of mortar.

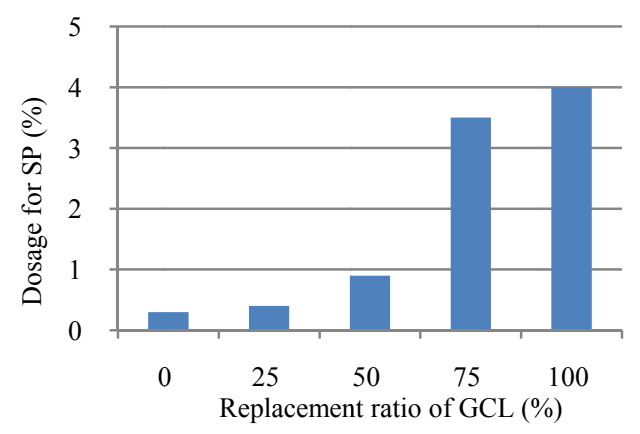

Fig. 6 Dosage for SP. 


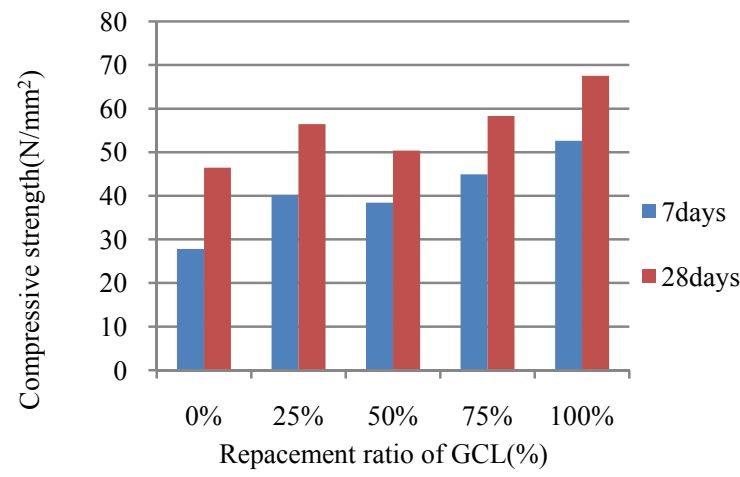

Fig. 7 Compressive strength of mortar.

cement paste and fine aggregate. Additional work is needed to confirm the effect of firmness of GCL.

\subsubsection{Drying Shrinkage}

Fig. 8 shows results of drying shrinkage test. As the replacement ratio of GCL increased, it is confirmed that drying shrinkage strain showed decreasing tendency. In these tests, when the GCL/ $\mathrm{S}_{\mathrm{n}}$ was $25 \%$, the drying shrinkage showed minimum value (line: $\mathrm{GCL} / \mathrm{S}_{\mathrm{n}}$ 25\%). To confirm this result, drying shrinkage test was done again. The results were almost the same.

It is also considered that this is due to the densification in transition zone at interface between cement paste and fine aggregate. Moreover, firmness of GCL, and mixture promotion has some effect on drying shrinkage, but additional work is needed to confirm this as well.

\subsubsection{Accelerated Carbonation Tests}

Fig. 9 shows results of the accelerated carbonation test. As the replacement ratio of GCL increased, the carbonation rate decreased.

The calcium ion and hydroxide ion derived from GCL fine aggregate might delay the progress of carbonation. The densification in the transitional zone also might have some effect.

\subsubsection{Self-healing Ability}

Fig. 10 shows the relationship between the amount of water leakage and the age after the start of the tests.

The figure shows the large difference in the initial amount of water leakage caused by the difference in the roughness of the specimen's split surface. Fig. 11 shows the relationship between the water leakage reduction rate and the age after the start of the test. The figure shows a similar trend for every replacement rate.

It is presumed that this self-healing ability would be due to the un-hydrated cement component in all of the mixes after curing for 28 days. Since all of the mixes

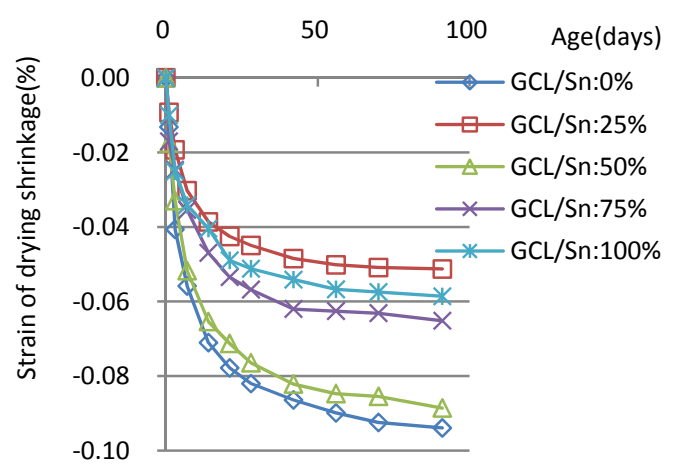

Fig. 8 Drying shrinkage of mortar.

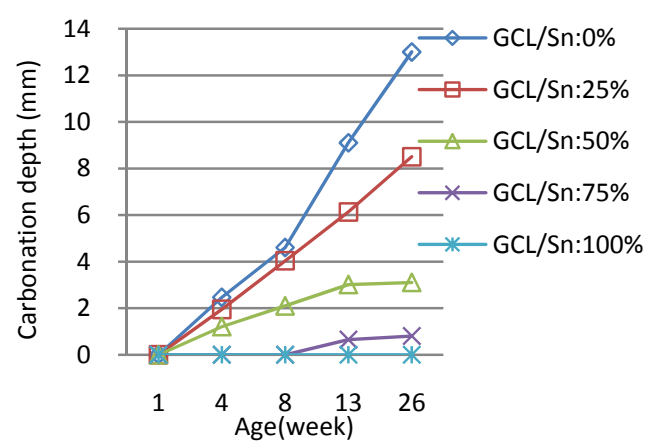

Fig. 9 Carbonation depth of mortar by accelerated carbonation tests.

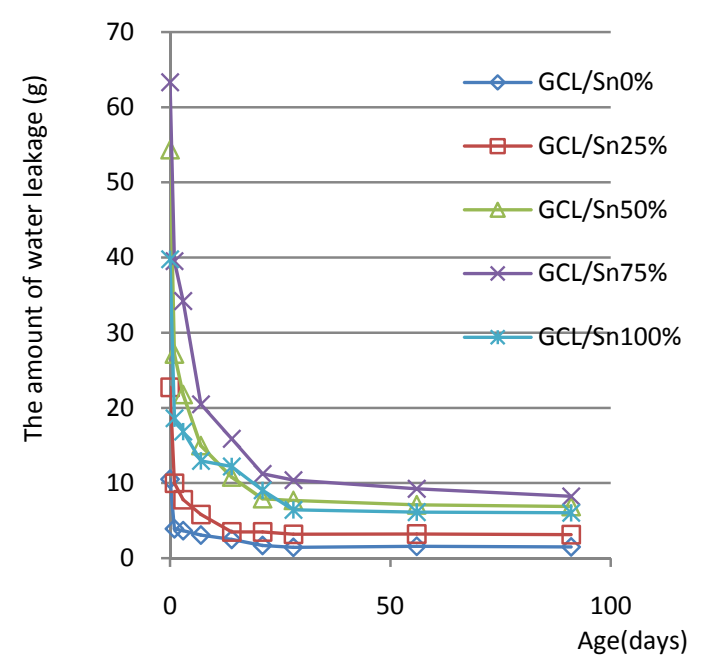

Fig. 10 Relationship between amount of water leakage and age after start of tests. 


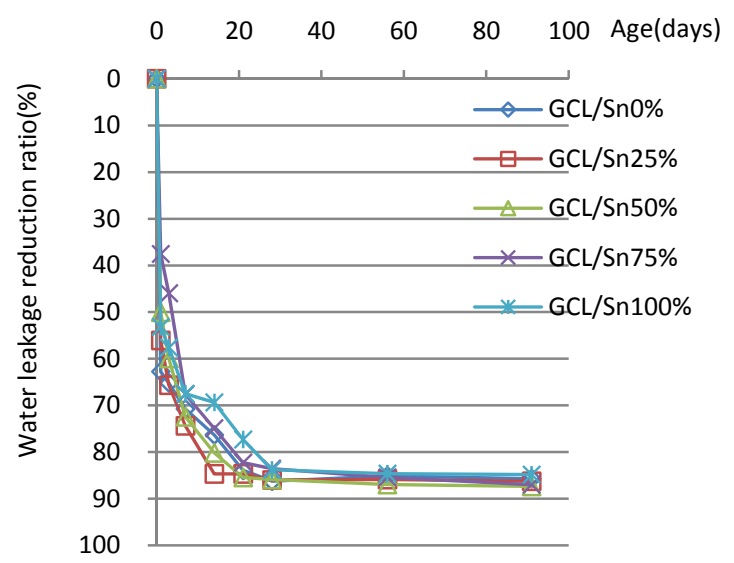

Fig. 11 Relationship between water leakage reduction rate and age after start of tests.

have the same unit cement content, they show almost the same self-healing ability. In these tests, the final reduction rate for all of the replacement conditions was approximately $85 \%$. Measurements will continue with additional experiments using more aged specimens.

\section{The Properties of Concrete Containing Gehlenite Clinker as Fine Aggregate}

\subsection{Mix Proportions}

Table 4 shows the mix proportions of the concrete. The concrete slump was targeted within $10 \pm 2 \mathrm{~cm}$ and air volume was targeted within $4.5 \pm 1.5 \%$ by controlling the amount of SP and AE.

\subsection{Testing Method}

\subsubsection{Fresh Property Test}

The concrete slump test was carried out in accordance with JIS A 1101 (equivalent to ISO 4109:1980) [8] and air volume measurement was carried out in accordance with JIS A 1128 (equivalent to ISO 4848:1980) [9].

\subsubsection{Compressive Strength Test}

The compressive strength test was carried out in accordance with JIS A 1108 (equivalent to ISO 1920-4:2005) [4]. The strength was measured at 7th and 28 th days after curing in water at $20{ }^{\circ} \mathrm{C}$. The size of cylindrical test specimens was $\varphi 100 \mathrm{~mm} \times \mathrm{h} 200$ $\mathrm{mm}$ in size and the number of specimens was three for each condition.

\subsubsection{Drying Shrinkage Test}

The drying shrinkage test was carried out in accordance with JIS A 1129 (equivalent to ASTM C157) [5]. The size of prismatic test specimens was $100 \mathrm{~mm} \times 100 \mathrm{~mm} \times 400 \mathrm{~mm}$ and the number of specimens was three for each condition. Measurements were started after curing test pieces for 7 days in water at $20{ }^{\circ} \mathrm{C}$. The drying conditions were at temperature: $20{ }^{\circ} \mathrm{C}$ and relative humidity: $60 \%$.

\subsection{Test Results and Discussion of Concrete Properties}

\subsubsection{Fresh Properties}

Fig. 12 shows the results of concrete slump test. Fig. 13 shows the air content of the concrete. Fig. 14 shows the additive rate for $\mathrm{SP}$ and $\mathrm{AE}$.

Concrete slump and air content were within the target range by using SP and AE. However, when the GCL replacement ratio increased, addition amount did not increase unlike the mortar.

\subsubsection{Compressive Strength}

Fig. 15 shows results of the compressive strength test. The compressive strength of GCL mixture was

Table 4 Mix proportions of concrete.

\begin{tabular}{|c|c|c|c|c|c|c|c|c|}
\hline \multirow{2}{*}{ Mix name } & \multirow{2}{*}{$\begin{array}{l}\text { GCL/S }{ }_{c}^{*} \\
\text { vol. }(\%)\end{array}$} & \multirow{2}{*}{$\mathrm{W} / \mathrm{C}(\%)$} & \multirow{2}{*}{ Air $(\%)$} & \multicolumn{5}{|c|}{ Unit content $\left(\mathrm{kg} / \mathrm{m}^{3}\right)$} \\
\hline & & & & $\mathrm{W}$ & $\mathrm{C}$ & $\mathrm{S}_{\mathrm{c}}$ & GCL & $\mathrm{G}$ \\
\hline GCL0\% & 0 & & & & & 859 & 0 & \\
\hline GCL25\% & 25 & & & & & 644 & 258 & \\
\hline GCL50\% & 50 & 55 & $4 \pm 1.5$ & 165 & 300 & 429 & 516 & 972 \\
\hline GCL75\% & 75 & & & & & 215 & 774 & \\
\hline GCL $100 \%$ & 100 & & & & & 0 & 1,032 & \\
\hline
\end{tabular}

${ }^{*} \mathrm{GCL} / \mathrm{S}_{\mathrm{C}}$ : Volume ratio of Gehlenite clinker fine aggregate to total fine aggregate. 


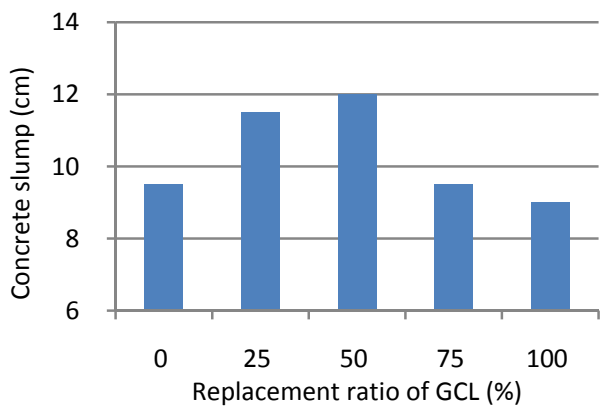

Fig. 12 Test results of concrete slump.

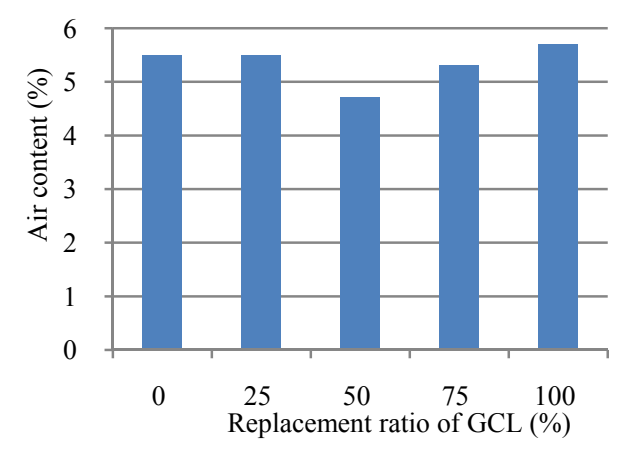

Fig. 13 Air content of the concrete.

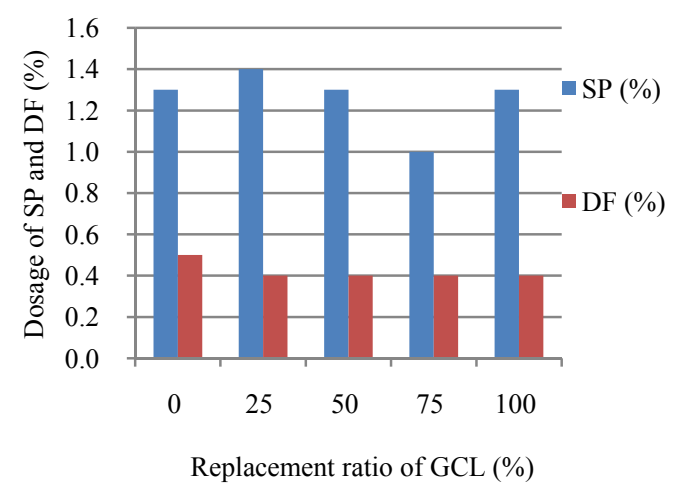

Fig. 14 Additional rate for SP and DF.

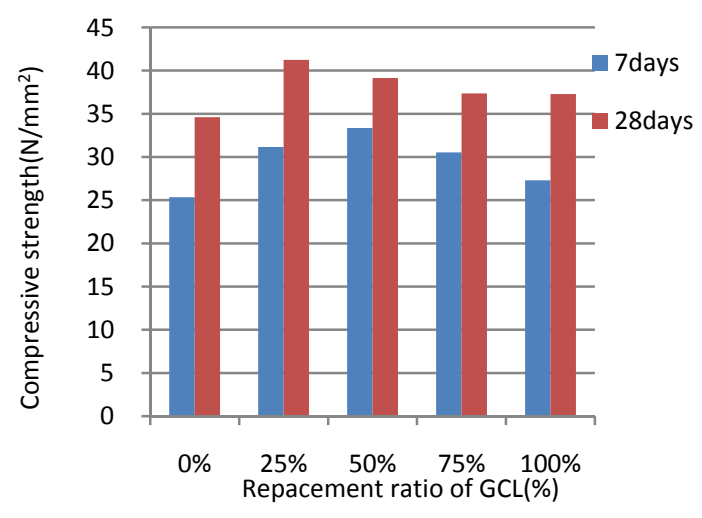

Fig. 15 Compressive strength of concrete.

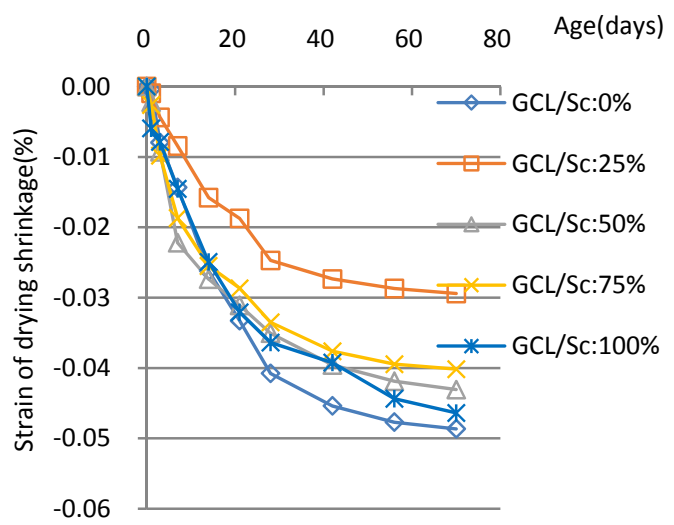

Fig. 16 Drying shrinkage of concrete.

higher than the non-mixed one. As same as the result of mortar, this is due to the densification in transition zone between cement paste and fine aggregate, and the firmness of GCL. The effect of replacing the clinker aggregate on compressive strength of concrete was almost same as that of mortar.

\subsubsection{Drying Shrinkage}

Fig. 16 shows results of drying shrinkage test. In these tests, when the $\mathrm{GCL} / \mathrm{Sc}$ was $25 \%$, the drying shrinkage was smallest, which is the same as the results of mortar. The results of concrete property tests showed the same performance as that of mortar.

\section{Investigation of Transition Zone between Cement Paste and Fine Aggregate}

From these test results, it was confirmed that compressive strength, drying shrinkage and resistance to carbonation were improved by replacement GCL to aggregate. And it was presumed that this would be due to the densification in transition zone at interface between cement paste and fine aggregate. Therefore, in order to investigate this, porosity distribution of mortar was measured. For this measurement, two kinds of specimens, were used one using natural river sand for all fine aggregate and another using GCL at replacement rate of $50 \%$ for fine aggregate. The samples were vacuumed dried and d-dried and then measured porosity distribution by a mercury porosimeter. The measurement range was from $3 \mathrm{~nm}$ 
Table 5 Pore size and porosity of mortar.

\begin{tabular}{lll}
\hline \multirow{2}{*}{ Pore diameter } & \multicolumn{2}{c}{ Porosity (vol. \%) } \\
\cline { 2 - 3 } & nature river sand & GCL/ $\mathrm{S}_{\mathrm{n}} 50 \%$ \\
\hline $3 \sim 5 \mathrm{~nm}$ & 0.29 & 1.97 \\
$5 \sim 50 \mathrm{~nm}$ & 2.75 & 6.3 \\
$50 \mathrm{~nm} \sim 2 \mu \mathrm{m}$ & 16.4 & 7.8 \\
$2 \sim 350 \mu \mathrm{m}$ & 3.83 & 2.41 \\
Total & 23.27 & 18.48 \\
\hline
\end{tabular}

to $350 \mu \mathrm{m}$. The average of 5 times measurements was used.

Table 5 shows the results of measurements. It is generally considered that capillary pores in the transition zone are rich in $50 \mathrm{~mm}$ to $2 \mu \mathrm{m}$ [10]. The void volume from $50 \mathrm{~mm}$ to $2 \mu \mathrm{m}$ of mortar using GCL is about half of that using natural river sand for all fine aggregate. Accordingly, it is confirmed that densification of transition zone is caused by using Gehlenite clinker as fine aggregate.

\section{Conclusions}

The Gehlenite clinker is produced by using large amount of industrial waste as raw materials in order to promote a recycling-oriented society. In this study, the properties of mortar and concrete containing Gehlenite clinker as fine aggregate were investigated.

Based on the test results, the following conclusions were reached.

Compared to mortar containing conventional fine aggregate, mortar containing Gehlenite clinker has higher compressive strength, less drying shrinkage, and lower carbonation rate.

When the GCL/S was $25 \%$, the drying shrinkage showed half amount of that of original mortar. It is considered that an optimum ratio of GCL/S can improve properties of mortar and concrete exists.

When the fine aggregate is replaced with Gehlenite clinker, it was confirmed that the porosity of the transition zone is reduced approximately to half. And it is thought that this causes the improvement of them.

The self-healing property based on reduction rate of water leakage showed similar trend in any replacement ratio of GCL. Considering the results, the un-hydrated cement particles have a large influence.

Based on the concrete properties, Gehlenite clinker as fine aggregate is applicable to practical use.

\section{References}

[1] Japan Standards Association. 2009. JIS A 5005 Crushed Stone and Crushed Sand for Concrete.

[2] ASTM C33 Standard Specification for Concrete Aggregates.

[3] Japan Standards Association. 2015. JIS R 5201 Physical Test Method of Cement.

[4] ISO 679. 2009. Cement-Test Methods-Determination of Strength.

[5] ISO 9597. 2008. Cement-Test Methods-Determination of Setting Time and Soundness.

[6] Japan Standards Association. 2005. JIS A 1116 Method of Test for Unit Mass and Air Content of Fresh Concrete by Mass Method.

[7] ISO 6276. 1982. Concrete, Compacted Fresh-Determination of Density.

[8] Japan Standards Association. 2006. JIS A 1108 Method of Test for Compressive Strength of Concrete.

[9] ISO 1920-4. 2005. Testing of Concrete-Part 4: Strength of Hardened Concrete.

[10] Japan Standards Association. 2010. JIS A 1129 Methods of Measurement for Length Change of Mortar and Concrete. 